\title{
Effects Of Enterprise Resource Planning Systems On Organizational Performance In Kitale Technical Training Institute, Kenya
}

\author{
Jepng'eno Mercy, Dr. Mike AmuhayaIravo (Ph.D) \& Dr. William Sakataka \\ A Research Project submitted to the Department of Business Administration in the School of Business in Partial \\ Fulfillment of the Requirements for the Award of the Degree of Master in Business Administration (Strategic \\ Management option) of -Jomo Kenyatta University of Agriculture and Technology
}

\begin{abstract}
An ERP system is a packaged business solution that is designed to automate and integrate business processes. It shares common data and practices across the enterprise and provides access to information in real time environment. ERP systems are intended to be a single comprehensive and integrated data-base which collects data from and feeds data into modular applications supporting virtually all of a company's business activities across functions and business units. The study has an overall objective of reviewing the effect of adopting ERPs on performance of public technical institutions, and specifically to examine how accessibility of data has improved organizational performance at Kitale Technical Training Institute, evaluate how database sharing has improved organizational performance at the Institute, to study how reporting for decision making has improved the performance of the institute and to examine how information sharing and networking has improved organizational performance at KTTI. The study will offer valuable contribution to theory and practice on the best approach to take in the process of adopting and implementing ERPs. The outcome will be applied in the development of an ICT Strategy document to guide institutions in terms of ERP adoption, which is relevant in most institutions in Kenya which helps in promoting reporting and availing of information to relevant offices to aid in decision making. Further, the study creates a forum for further discussions on best practices and strategies to implement an ERP system. The study will use the descriptive survey design which will analyze factors such as behavior, attitudes, values and characteristics. This research design is very suitable for this study as it will greatly aid in describing the effects of adopting ERPs on performance of the institute under study. The study sample will be drawn from a population comprising of both teaching and non-teaching staff. Data collection will be done through the use of validated questionnaires, observations and interviews with key players in the Institute.
\end{abstract}

\section{Introduction}

As defined by Deloitte (1998), an ERP system is a packaged business software system that allows a company to; automate and integrate the majority of its business processes, share common data and practices across the entire enterprise, and produce and access information in a real-time environment. The use of such systems in organizations for purposes of managing processes such as students' admission and registration, library management, procurement and stores management, fee collection and finance management among others enhances delivery of services in public technical institutions. In embracing ERPs, organizations should ensure there is secure integration and communication with other relevant information systems. Use of ERPs leads to processes by which technical institutes transform paper based processes and procedures into a computerized system that can capture all the functional processes and functional data information flows to aid in management.

According to studies done by Santhanam and Hartomo (2003), Baradang et al (1999) and Hammer and Champy (1993) among others, ICT resources can have a general positive effect on business performance and services rendered in terms of reduced process cycle times, turnaround times and increased productivity. The role of IS and ICTs is fundamental in bringing about transformational change in public service provision and administration (OECD, 2005). The need to increase efficiency is one of the most important reasons to implement an ERP system (Chang et al, 2000).ICT adoption by institutions helps to enhance productivity by reducing start-up time and cutting red tape. In addition in their study Holland and Light (1999) highlighted that ERP implementation may follow two paths, i.e. the choice of a standardized ,almost ready-to-use package, with little adjustments required, and the customization of an ERP system to tailor it to the organization's needs. The first option appears to be more likely than the second one (Morton and Hu, 2008) especially because it is less expensive. However, this enforced standardization may not fit the organization's characteristics and, in turn, this may lead to failure of the ERP system's implementation (Morton and Hu, 2008).

An Enterprise Resource Planning system(ERP) is an advanced Information System(IS); it provides a comprehensive overview of the organization and a common database in which business transactions are 
recorded and stored(Umble,Haft and Umble, 2003).Moreover, ERP systems might help to reduce costs and improve inefficient processes (Harris,2006). The use of such systems, in technical training institutes can present reliable and timely information on student enrolment, fee collection and balances, library management, procurement and stores balances, expenditure control and reporting has had a negative effect on budget management, student management and inventory management.

ERP applications do not only address organizational systems from a business process change perspective, but also, the software configuration is geared towards creating a seamless and integrated value chain,(Al-Mudimigh et al. 2001). According to studies done by (Davenport et al., 1998), ERP systems should not be looked at as a tool with fixed measurable output but rather as a corporate infrastructure designed to provide a standardized and integrated business.

Use of ERPs leads to processes by which technical institutes transform paper based processes and procedures into a computerized system that can capture all the functional processes and functional data information flows to aid in management.

In addition to the above institutions that fall under the auspices of the ministry of Education Science and Technology, other governmental ministries operate institutions that provide specialized technical training. Overall, the management of Technical, Industrial, Vocational and Entrepreneurship Training institutions is spread over several ministries, which makes co-ordination of their activities and maintenance of training standards difficult. The supervision of most of these institutions is left to individual ministries and private sector that often lack the capacity to assure quality and high standards of training and management (MOEST 2002).

Kitale Technical Training Institute has implemented information and communication technology systems with a view of automating processes used in engagement with their clientele.Initially the institute was using the manual system which led to poorly controlled resources, often resulting in large build of arrears, excessive borrowing and misallocation of resources, undermining the effectiveness and efficiency of service delivery. This led the institute into adopting the use of ERPs as a means of mitigating these challenges. It has been established that efficient and effective application of ICT resources in business processes can yield tangible benefits (Hosseini, 2005).

Performance of Technical Training Institutions in Kenya has remained a big challenge in the modern competitive business environment. Regardless of the internal control practices, it is evident that Technical Training Institutions in Kenya are inefficient and ineffective based on their practices. However, the motive behind this study is to investigate the effect of internal controls in performance of technical institutions in Kenya thus coming up with appropriate measures to reduce the felt difficulty among Technical Training Institutions in Kenya. (MOEST, 2002).

The need to increase efficiency is one of the most important reasons to implement an ERP system (Chang et al, 2000).ICT adoption by institutions helps to enhance productivity by reducing start-up time and cutting red tape. In addition in their study Holland and Light (1999) highlighted that ERP implementation may follow two paths, i.e. the choice of a standardized, almost ready-to-use package, with little adjustments required, and the customization of an ERP system to tailor it to the organization's needs. The first option appears to be more likely than the second one (Morton and $\mathrm{Hu}, 2008$ ) especially because it is less expensive. However, this enforced standardization may not fit the organization's characteristics and, in turn, this may lead to failure of the ERP system's implementation (Morton and Hu, 2008).

ERP systems are often implemented not to replace legacy systems but as part of an organization's effort to modernize and differentiate itself (Reimers2003).According to (Gupta 2008) ERP systems have gained widespread appeal in the $21^{\text {st }}$ century owing to their "do it all" approach to organizational management. With more users seeking to link application systems to departmental processes, public universities in Kenya are seeking ways to integrate their operations in a bid to cut on operational costs, offer timely response to their clients and interact with their stakeholders in 'real time'. To meet these requirements, public universities in Kenya have resorted to use of ERP systems to automate their operations on a standardized platform in line with their strategic plans. With past studies laying emphasis on ERP systems in business scenarios in Kenya, the study herein sought to explore implementation of ERP systems in Kenyan public universities in their quest to improve quality of their service to meet regional as well as global standards.

\subsection{Problem Statement}

Public Technical Institutions have been faced by a myriad of challenges in the day to day operations. The challenges include the problems of lack of adequate infrastructure such as Local Area Networks for connectivity between departments, computers and related accessories; as a result, information cannot be availed in a timely manner. Inadequate allocation of financial resources to ICT which is meant to drive adoption of technological systems has been a problem that has negated plans to improve processes in the institution. The Institution is also faced with the challenge of having semi skilled staff who have tended to resist adoption of 
ERP's and additionally has been a challenge in having the institution benefit fully from exploitation of functionalities availed.

\subsection{Research Objectives \\ 1.3.1 Overall Objective}

The overall objective of the study is to review the effect of using ERPs on performance of Kitale Technical Training Institute.

\subsubsection{Specific Objectives}

a) To examine how accessibility of data has improved organizational performance at Kitale Technical Training Institute

b) Evaluate how database sharing has improved organizational performance at the Institute

c) To study how reporting for decision making has improved the performance of the institute

d) To examine how information sharing and networking has improved organizational performance at KTTI

\subsubsection{Theory of Organizational Information Processing}

\section{Theoretical Framework}

This theory was by developed by (Galbraith, 2005). The theory identifies three important concepts: information processing needs, information processing capability, and the fit between the two to obtain optimal performance in organizations. According to the theory, organizations need quality information to cope with environmental uncertainty and improve their decision making. Environmental uncertainty stems from the complexity of the environment and dynamism, or the frequency of changes to various environmental variables. The theory further postulates that organizations have two strategies to cope with uncertainty and increased information needs for their management processes:

(1) Develop buffers to reduce the effect of uncertainty, and

(2) Implement structural mechanisms and information processing capability to enhance the information flow and thereby reduce uncertainty.

As can be seen from the model, organization design strategy has sub units. These sub units require an integrated IT system that improve information flow and reduce uncertainty within organizational sub units. Increasing the capacity to process information required in management processes which require (1) investment in vertical information systems and (2) creation of lateral relations to portray an image of how the levels of management interact in the management processes. Creation of slack resources and self-contained tasks that reduce the need for information processing after a satisfactory confirmation that indeed output of a process doesn't require further intervention of an information processing system. Increasing the capacity to process information and reducing the need for information processing are products aimed at fulfilling management goals which are key entities of management (Markus et.al, 2000).

A lot was borrowed from this model for this research, especially when we talk of integrating ICT in management processes of public technical institutions in Kenya, and understanding that ICT can indeed play greater roles towards improving the processes of management in technical institutions. The model was adopted because accurate and timely information is a key element in management processes. Acquiring this information requires a processing model which cannot be complete without focusing on Information and Communications Technology infrastructure.

\subsubsection{The Theory of Sociotechnical System (STS)}

STS advocates the joint consideration of social and technical factors when introducing new technologies into an organization. This theory considers organizations as consisting of two interdependent systems; a technical system and a social system. The technical system focuses on equipment and processes, while the social system emphasizes on people and relationships, (Shani et.al, 1992). This theory is applicable in Kitale Technical Training Institute in that other than putting into consideration the technical factors such as laying down information technology infrastructure such as networking the institute and buying computers, the institute has also laid emphasis on the social system which includes hiring of skilled staff and training the existing staff to enable successful adoption and implementation of ERPs.

\section{The Technical System}

The technical system of an organization consists of tools, techniques, devices, artifacts, methods, configurations, procedures and special knowledge used by organizational members to acquire input and to transform input into output (Perinea and Mc Clean, 1994). The extent of automation of a given technical system is crucial to the productivity of an organization. A typical quantitative measure of the extent of automation is the 
percentage of automated equipment among the total number of machine tools. A larger percentage indicates a higher extent of automation.

\section{The Social System}

The social system of an organization comprises the individuals who work in the organization and the total of their individual and social attributes. Specifically, a social system encompasses individuals' characteristics and relationships within and between groups. Individuals' characteristics are related to employee's aptitudes, skills, education, attitudes and beliefs. Relationships include lateral and vertical relationships between supervisors and subordinates. The socio-technical perspective describes the devices, tools and techniques needed to transform inputs into outputs to enhance the organizational performance. (Tasmin and Woods ,2007) showed that the socio-technical model (Figure 1) matched with the Knowledge Management proposed elements of leadership and culture (infoculture), technology (infrastructure) and process and measurement (infostructure). Pan and Scarbrough (1998) stated that "the socio-technical perspective thus adopts a holistic approach which highlights the interweaving of social and technical factors in the way people work".

\section{Conceptual Framework}

Independent variables

Dependent variables

Financial Information

- Number of financial reports generated by the ERPS

\section{Information sharing and networking \\ - LAN connectivity \\ Database sharing \\ - Number of modules connected to the central server}

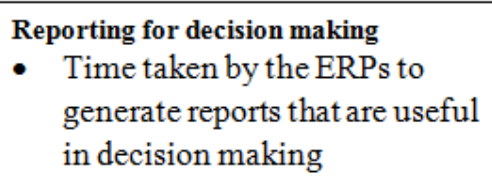

\section{Accessibility}

- Ratio of computers to users
OrganizationalPerformance

- Time taken to serve clients

- Availability of real-time reports for decision making

This chapter spells out on the method of undertaking the research; the target population, design, sampling, data collection, analysis and ethical issues involved. The research adopted a descriptive survey design. According to Mugenda\&Mugenda (2003), a descriptive research determines and reports the way things are. This type of research design was deemed appropriate as it involved describing things such as behavior, attitudes, values and characteristics. In view of this, this research design was deemed suitable for this study as it helped in describing the effects of automation on performance of public technical institutions.

The study covered Kitale Technical Training Institute, in Trans Nzoia County with combined staff strength of 170 staff. The population was drawn from departments namely Administration, Accounts, Library department and procurement department. Clients of Kitale Technical Training Institute were also involved in the study so as to ascertain the effect of adoption of ERPs on performance of Public Technical Institutions.

The sample that was used in this study is fourty six comprising of heads of departments, ICT personnel, system users and other lower cadre staff of the Institution which was believed to be sufficient given that they are the persons who interact with the system on daily basis as they carried out their duties and therefore they can tell if automating of the institute's processes have any effect on the general performance of the institution. 
Effects Of Enterprise Resource Planning Systems On Organizational Performance In Kitale...

Table 3.1: Composition table of sample design

Composition of sample

\begin{tabular}{|l|l|}
\hline CATEGORY & NO.TO INTERVIEW \\
\hline Heads of Department & 10 \\
\hline Technical Personnel & 5 \\
\hline System users & 31 \\
\hline Total & $\mathbf{4 6}$ \\
\hline
\end{tabular}

The study used random sampling technique in collection of data. This is a sampling method in which all members of a group or population had an equal and independent chance of being selected.

The data collection instrument that the study used included questionnaires for collection of primary data and data mining instrument for collection of secondary data. Data mining involved sifting through information in the existing databases for useful information on patterns and trends. The choice of this instrument was prompted by its reliability and validity of the answers. This is so because the interaction between the researcher and the respondents, which could bias the responses to the questions in the questionnaire, was minimal. During the process of undertaking this study, data was collected from HOD'S in various departments and sections that are currently served by system; this enabled the preparation of an objective report that reflected the true picture effects of automation on performance of public technical institutions. Data was collected from staff by way of questionnaires which was be administered at the institutions offices.

According to Mugenda\&Mugenda (2003) validity is the accuracy and meaningfulness of inferences based on research results. It comprises of the degree to which results obtained from the data analysis represent the subject of the study. To ensure validity, accuracy of research data was put into consideration to represent variables of the study. To realize this, all the independent and depend variables were included in the study questionnaire. Reliability of research as argued by Mugenda\&Mugenda (2003) refers to the degree to which a research instrument yields consistent results or data after repeated trials. Reliability in research can be influenced by random error. This may arise from inaccurate coding, ambiguity of instructions to respondents, fatigue on researcher and respondents and bias. To address reliability of the research, pre-testing of the research instruments through a pilot test was done. The test retest method used as observed by Ngechu (2004) helped in obtaining a coefficient of reliability and suitability of the instrument. If the coefficient is low, a review of the instrument would have been done. If the coefficient was high, which happened to be the case, the study instrument used was deemed to have high test-retest reliability in carrying out the study.

After data collection, the next phase was that of data analysis, which involved a review of all data collected. This was meant to ensure that all data conformed to a prescribed format so that useful information could be highlighted thus resulting in the success of the research. Data analysis involved use of descriptive analysis which entailed use of tables to present summaries of findings and also use of percentages (\%).A regression model was used to show the effect of automation on performance of public technical institutions.

\section{Discussion Of Research Findings}

Information was sought regarding how the adoption of ERPS had solved prevailing challenges faced previously in functional systems within the institution. From the responses received, it became evident that a lot of benefits had been realized with the adoption and use of ERP within the institution which were as follows; Real time generation of reports, Increased accessibility of records, Improved decision making, Accountability and Transparency, Quick retrieval of information, Minimized duplication and Accurate financial reports.

The use of ERP led to generation of reports on real time basis, as a result of a single central database where records are stored. As a result of this, any system user could access reports as and when need be based on their assigned role. Additionally, respondents also indicated that this had led to improved decision making since, reports could be acted upon faster as compared to manual based records which in the past took time to prepare. More importantly there has been increased accessibility of records of varying nature such as financial and student records. This was made possible by the fact that, the ERP system spans the entire institution and has modules serving various functional areas of KTTI. Data elements generated in these functional areas are all saved in the Central Database, making complete records available across departments.

Additionally there has been increased transparency and accountability due to the use of ERP systems in the institution. This is indicated by the responses gotten from the respondents who were of the view that with the use of ERP systems, all financial transactions were more transparent since approvals through various levels was sought via the system and this resulted in members of staff in various levels of management being aware of impending financial commitments as well as expenditures. This in essence enhanced accountability of all officers concerned in various levels of management and functional areas. The responses received also indicated that the use of ERP system had led to reduced duplication of records; this was realized since systems work with unique identifiers since as identification numbers and admission numbers which once entered were available in the system across the organization in various modules 
The researcher sought to know the achievements that the use of ERP's had brought to the organization. A majority of respondents responded that one of the achievements that the institution had gotten from implementation of ERP was accessibility of information. The use of ERP, enabled members of staff at various levels of management to be able to retrieve information and reports as and when needed, speeding up the need to respond to queries arising. The respondents' agreeing with this accounted for $64 \%$ of the total respondents.

The number of respondents who agreed that database sharing had been one of the achievements were 22 and accounted for $48 \%$ of the total respondents. Database sharing implies that data and information is easily shared across departments, ensuring consistency. $40 \%$ of the respondents agreed that one of the benefits that ERP use had brought to the organization was on financial information. This implies that financial reports could be extracted easily unlike before when the records were in manual form. Asked whether achievements as listed below had improved their performance and that of the organization; Accessibility to information, Database sharing, financial information, reporting for decision making and Information sharing and networking. All respondents agreed that the achievements listed above had led to improved performance of their duties as well as that of the organization.

\section{Regression Analysis}

Regression analysis is a statistical tool for evaluating the relationship between a continuous dependent variable and one or more independent variables. If tests of regression model are significant then the model is statistically significant.

Table 4.25: Model summary table

\begin{tabular}{|l|l|l|l|l|}
\hline \multicolumn{4}{|l|}{ Model Summary } \\
\hline Model & $\mathrm{R}$ & $\mathrm{R}$ Square & Adjusted R Square & Std. Error of the Estimate \\
\hline 1 & $.927^{\mathrm{a}}$ & .859 & .841 & .469 \\
\hline a. Predictors: (Constant), X5, X4, X3, X1, X2 \\
\hline
\end{tabular}

From the results of regression analysis, the model summary table indicates that the coefficient of multiple variables is .859 ; therefore, about $85.9 \%$ of the variation in performance improvement out of use of ERP can be explained by accessibility, database sharing, reporting, information sharing and availability. The regression equation appears to be very useful for making predictions in this case as the value of $R^{2}$ is close to 1 .

Table 4.26: Analysis of variance table

\begin{tabular}{|c|c|c|c|c|c|c|}
\hline \multicolumn{7}{|c|}{ ANOVA $^{\text {a }}$} \\
\hline \multicolumn{2}{|c|}{ Model } & Sum of Squares & df & Mean Square & $\mathrm{F}$ & Sig. \\
\hline \multirow[t]{3}{*}{1} & Regression & 53.653 & 5 & 10.731 & 48.756 & $.000^{\mathrm{b}}$ \\
\hline & Residual & 8.803 & 40 & .220 & & \\
\hline & Total & 62.457 & 45 & & & \\
\hline \multicolumn{7}{|c|}{ a. Dependent Variable: Organizational Performance } \\
\hline \multicolumn{7}{|c|}{ b. Predictors: (Constant), X5, X4, X3, X1, X2 } \\
\hline
\end{tabular}

The significance level is set at $5 \%$. The results are at a significant level of $.000^{\mathrm{b}}<0.05$ level of significance, indicating that there exists enough evidence to conclude that at least all of the predictors are useful for predicting the performance of various functions at the institution from use of ERP.

\section{Conclusion}

Kitale Technical Institute has invested heavily in Management Information Systems in order to improve efficiency and effectiveness in delivery of services and execution of functional operations. Use of ERP's is viewed as a means of ensuring that they manage their core functions in a proper manner geared towards achieving their objectives. It is also important that a project team and a project leader be put in place so as to focus on the project objectives. An operational level project team is also essential to ensure that departmental heads keep submitting input that adds value to projects of similar nature.

The changeover method used to change from the old to the new system was a mix of phased and direct changeover. This is largely due to the fact that this was the method deemed least expensive, guarantee that there was no data loss and also largely due to the fact that there was inadequate resources allocated for the process. The study has also shown that it is essential that top management actively take part and embrace the new processes so as to offer leadership and ensure the success of the process, this is because of they will have the ability to put resources on the line for the success of the project. 


\section{References}

[1]. Abdullah Al-Mudimigh (2001).Enterprise Resource Planning: Taxonomy of critical factors. European Journal of Operational Research146 (2): 352-364 (2003)

[2]. Akbulut and Allen (2002). Handbook of Research on ICT-Enabled Transformational Government

[3]. Al-Sehali and Soh (2005). Sociotechnical Enterprise Information Systems Design and Integration

[4]. Angerer.A(2005).The Impact of Automatic Store Replenishment Systems on Retail

[5]. Baxter and Somerville (2010).Socio-Technical Systems: From Design methods to Systems Engineering

[6]. Bhardwaj and Singh.(2011).Automated Integrated University Examination System

[7]. Bhatti (2005) E-Adoption and Technologies for Empowering Developing Countries

[8]. Chang, S.I., Gamble, Sofied ,Smythe E and Timbrell, G. (2000). A Delphi examination of public sector ERP implementation issues.Proceedings of the Twenty First International Conference on Information Systems, Brisbane, Queensland, Australia, 494-500

[9]. Davenport and Chong Siong Choy (1998) Critical Factors in the Successful Implementation of Knowledge Management. Journal of Knowledge Management Practice, June 2005

[10]. Diamond, J. and Khemani, P. (2006).Introducing Financial Management Information Systems in Developing Countries, Volume 5 No. 3

[11]. Dixit, A and Prakash, O. (2011).A study of Issues affecting ERP implementation in SME's

[12]. Elisabeth J. Umblea, Ronald R. Haft b , Reimers and M. Michael Umble (2003) Enterprise resource planning: Implementation procedures and critical success factors. European Journal of Operational Research 146 (2003)241-257 w

[13]. Guidelines and Functoinal Requirements for Electronic Records Management Systems(2008).International Council on Archives, Principle and functional requirements for records in Electronic office environment-Module 2:

[14]. Gupta Deepak (2008).IT Enabled Practices and Emerging Management Paradigms Heidenh of, G., Grandvoinnet, H., Kianpour, D., Rezaian, B. (2002). Design and Implementation of Financial Management Systems: An African Perspective

[15]. Heiskanen and Markus (2000) Information Systems Outsourcing: Towards Sustainable Business Value

[16]. Holland, C.R. and Light, B (1999). A critical success factors model for ERP implementation, in proceedings $7^{\text {th }}$ European Conference on Information Systems.

[17]. Hosseini (2005). Delivery and Adoption of Cloud Computing Services in Contemporary Organizations

[18]. Islam, M and Alam, M (1999). An overview of the prospects and challenges of office systems and automation,

[19]. Javier Corrales and Frank Westohoff, (2006) Information Technology Adoption and Political Regimes.

[20]. Kraemer and King (1977) Modern Public Information Technology Systems: Issues and Challenges

[21]. Laudon, K.C. and Laudon J.P.(2003): Management Information Systems: Managing the Digital Firm, 7th ed., New Jersey: PrenticeHall.

[22]. M.L.Markus and C.Tanis, 2000, The enterprise systems experience from adoption to success, in framing the Domain of IT Research; Glimpsing the Future Through the Past.(PinnaflexEductionalResources:Cincinnati,OH)

[23]. MoEST (2000).Linking TVET institutions and industry in Kenya.International Journal of Economy, Management and Social Sciences, 2(4) April 2013, Pages: 91-96

[24]. Morton, N.A. and Hu, Q (2008).Implications of the fit between organizational structure and ERP: A structural contingency theory perspective. International Journal of Information Management, 28 (5),391-402

[25]. Mugenda, O.M \&Mugenda, A.G (2003).Research Methods, Quantitative and Qualitative Approaches. Nairobi, Kenya. A.C.T.S Press

[26]. O'Brien,J, Rand and Marakas G (2009) Management Information Systems (9 ${ }^{\text {th }}$ Edition) NewYork, N.Y McGraw-Hill Irwin

[27]. Otieno, Jim Odhiambo (2010).Enterprise Resource Planning Systems implementation and upgrade (A Kenyan Study)

[28]. Richard Heeks (2002) International Practice in IT-Enabled Public Sector Reform

[29]. T.M Somers and K.G Nelson, The Impact of Critical success factors across stages of Enterprise Resource Planning Implementations, Annual Hawaii International Conference on System Sciences.

[30]. Tasmin,R,Oyedun and Rusuli,M (2007).Applicability of Socio-Technical Model in working system of modern organizations

[31]. Tripathi.K and Mohini (2011).A Study of Information Systems in Human Resource Management (HRM)

[32]. Tsichritzis (1999). Handbook on Information Technologies for Education and Training

[33]. Umble,E.J., Haft, R.R and Umble M.M (2003). Enterprise Resource Planning: Implementation procedures and critical success factors. European Journal of Operational Research, 146, 241-257

[34]. United States Agency for International Development. (2008).Integrated Financial Management Information Systems: a Practical guide. Publication of United States Agency for International Development. Fiscal Reform and Economic Governance Task Order Vol 7

[35]. YaseminBal,SerdarBozkurt and EslnErtemsir(2012).The Importance Of Using Human Resources Information Systems (HRIS) And a Research On Determining The Success Of HRIS, 